\title{
Impact of Body Mass Index on Luteinizing Hormone Secretion in Gonadotropin-Releasing Hormone Stimulation Tests of Boys Experiencing Precocious Puberty
}

\author{
Hae Sang Lee Hong Kyu Park Jung Hee Ko You Jin Kim Jin Soon Hwang \\ Department of Pediatrics, Ajou University Hospital, Ajou University School of Medicine, Suwon, Korea
}

\section{Key Words}

Body mass index $\cdot$ Precocious puberty $\cdot$ Luteinizing hormone

\begin{abstract}
Objective: Excess adiposity may influence various aspects of pubertal development, including the timing of pubertal initiation and hormonal parameters during puberty. The aim of the study was to evaluate the impact of body mass index (BMI) on luteinizing hormone (LH) secretion to gonadotropin-releasing hormone $(\mathrm{GnRH})$ stimulation test in boys with precocious puberty. Methods: Boys with precocious puberty, who were normal weight, overweight, and obese underwent GnRH stimulation tests between 2003 and 2010. Subjects were classified as normal weight $(B M I \geq 5$ th percentile and $\mathrm{BMI}<85$ th percentile), overweight (BMI $\geq 85$ th percentile and $\mathrm{BMI}<95$ th percentile), and obese (BMI $\geq 95$ th percentile). Results: Of 56 children whose data were included in the final analysis, mean age at diagnosis was $8.7 \pm 1.0$ years. The majority of boys were of normal weight $(n=28,50 \%)$, while 15 children (26\%) were overweight, and 13 (23\%) obese. Peak LH levels after GnRH stimulation were $19.8 \pm 8.8,9.0$ \pm 3.5 , and $8.1 \pm 4.0 \mathrm{mlU} / \mathrm{ml}$ among normal weight, overweight, and obese subjects, respectively $(p<0.001$ for all
\end{abstract}

comparisons). By multivariate analysis, there was a significant negative association of BMI with peak-stimulated $\mathrm{LH}$ level. Conclusions: The higher BMI is associated with lower $\mathrm{LH}$ response to the $\mathrm{GnRH}$ stimulation test in boys experiencing precocious puberty. In boys with precocious puberty, BMI should be considered when interpreting GnRH stimulation test.

Copyright $\odot 2012$ S. Karger AG, Basel

\section{Introduction}

Childhood obesity has become a major health concern in recent decades. The incidence of childhood obesity is rising across the globe in conjunction with obesity related comorbidities $[1,2]$. Excess adiposity may influence various aspects of pubertal development, including the timing of pubertal initiation and hormonal parameters during puberty. Several recent studies suggest that over the last century the onset of the pubertal development has begun to occur earlier, and there is strong evidence that an increase in childhood obesity in children over the same time period is a major contributing factor [3-5]. Although many studies show that obesity is associated with sexual maturation in adolescent girls and 
young female adults [6-8], limited research has been conducted in boys exploring the likelihood of a similar association.

Precocious puberty is defined as the progressive onset, accompanied by advancement of skeletal age, of secondary sexual characteristics before the age of 8 years in girls and 9 years in boys [9]. Puberty is initiated centrally, with gonadal function being driven by increased secretion of gonadotropin-releasing hormone $(\mathrm{GnRH})$ and gonadotropin. Among the many factors influencing the neural networks controlling GnRH secretion, information about the status of nutrition is one of the cornerstones in the control of pubertal onset and progression [10-12]. Adipocytes secrete leptin in direct proportion to adipose tissue mass as well as nutritional status. Leptin and its regulation may be important in the initiation and or progression of puberty and may play a role in the earlier onset of puberty in obese children compared to children of normal weight $[11,13]$. However, recent studies have demonstrated that the earliest hormonal change of puberty, increased levels of luteinizing hormone (LH) at sleep onset, was blunted in prepubertal healthy girls with excessive body mass index (BMI) [14, 15]. In one recent study by Birkebaek et al. [16], they found a significant increase in LH and follicle-stimulating hormone (FSH) levels in obese boys during weight reduction and an inverse relationship between $\mathrm{LH}$ and BMI changes.

The aim of the present study was to investigate the influence of BMI on abnormal sexual maturation by analyzing gonadotropin response to $\mathrm{GnRH}$ stimulation tests in boys with precocious puberty.

\section{Methods}

\section{Subjects}

A total of 104 boys formed the study cohort for our report. All subjects were referred to Ajou University Hospital between 2003 and 2010 for signs of early puberty such as testicular enlargement, pubic hair, and voice break. In some boys, testicular enlargement seems to have started after 9 years of age, and such boys were subsequently reclassified as having normal puberty. Eight boys were excluded because of insufficient blood samples, and 12 boys were excluded based on GnRH stimulation tests. Subjects in the final analysis included 56 boys with precocious puberty (fig. 1). All subjects underwent GnRH stimulation tests as part of their evaluation. Precocious puberty was diagnosed according to the following criteria: (1) objective testicular volume $>4 \mathrm{ml}$ (testicular volume $>4 \mathrm{ml}$ ) before 9 years of age; (2) advanced bone age $>1$ year above chronological age; (3) pubertal LH peak values (cut-off value $\geq 5 \mathrm{IU} / \mathrm{l}$ ), and (4) elevated serum testosterone levels (testosterone $>0.8 \mathrm{nmol} / \mathrm{l}$ ) with the GnRH stimulation tests performed be- fore 9 years of age [17]. Precocious puberty with an identified etiology, such as brain tumor or cranial irradiation, was excluded. Plasma 17-hydroxyprogesterone and testosterone concentrations were measured to exclude abnormal androgen secretion. Plasma thyroxine and thyroid-stimulating hormone concentrations were measured to exclude hypothyroidism. The study protocols were approved by the Institutional Review Board of the Ajou University Hospital.

\section{Study Design}

Subjects were not taking medications known to affect the reproductive axis, and none had used hormonal medications before the study. No subject experienced chronic illnesses or hirsutism. The hypothalamic-pituitary-gonadal axis was investigated by measuring plasma LH and FSH peak concentrations under GnRH (100 $\mu \mathrm{g}$ Relefact; Sanofi-Aventis, Frankfurt am Main, Germany) stimulation. Basal serum samples were obtained prior to $\mathrm{GnRH}$ injection. Post-stimulation samples for measurement of LH, FSH, and testosterone levels were acquired 30, 45, 60, and 90 min after injection. Serum LH, FSH, and testosterone levels were measured by immunoradiometric assay (BioSource SA, Nivelles, Belgium). Patients' height, weight, pubertal status, thyroid function, and bone age were collected from clinical charts and electronic medical records. The volume of each testis was estimated by comparative palpation with the orchidometer of Prader [18]. Pubertal stage was determined according to Marshall and Tanner [19]. Bone age was determined by a single pediatric endocrinologist, using Greulich and Pyle's standards [20]. BMI was determined and the BMI standard deviation score (SDS) according to chronological age calculated using the 2007 Korean National Growth Charts [21]. All precocious puberty patients had normal magnetic resonance imaging (MRI) studies of the hypothalamic-pituitary area.

\section{Laboratory Measurements}

Serum LH and FSH levels were measured by immunoradiometric assay with analytical sensitivity of 0.2 and $0.1 \mathrm{IU} / \mathrm{l}$, intraassay coefficient of variation (CV) ranging from 1.4 to $3.9 \%$ and 1.1 to $2.0 \%$, and inter-assay CV ranging from 3.4 to $8.0 \%$ and 2.4 to $4.4 \%$, respectively (BioSource SA). Testosterone levels were determined on radioimmunoassay with analytical sensitivity of 0.3 $\mathrm{nmol} / \mathrm{l}$, intra-assay $\mathrm{CV}$ ranging from 4.0 to $7.0 \%$, and inter-assay CV ranging from 4.2 to $8.1 \%$ (RIA; Coat-A-Count, Diagnostic Products, Los Angeles, Calif., USA).

\section{Statistical Analysis}

Statistical analysis was performed using SPSS version 12.0 (SAS Institute, Chicago, Ill., USA). For classification of clinical parameters according to BMI, which was divided into normal (BMI $\geq 5$ th percentile and BMI $<85$ th percentile), overweight (BMI $\geq 85$ th percentile and BMI $<95$ th percentile), and obese (BMI $\geq 95$ th percentile), ANOVA was performed with Tukey's test. The Pearson correlation between peak LH and BMI was additionally assessed. To determine significance of association with peak $\mathrm{LH}$, linear regression was performed for uni- and multivariate analyses with stepwise variable selection, including age at detection, BMI SDS, weight SDS, height SDS, bone age, testicular volume, basal LH, basal FSH and basal testosterone levels. Statistical significance was defined as $p<0.05$. Results were presented as mean \pm SD unless stated otherwise. 
Fig. 1. Diagram of 104 boys who were referred to a single tertiary pediatric endocrine center for evaluation of early puberty.

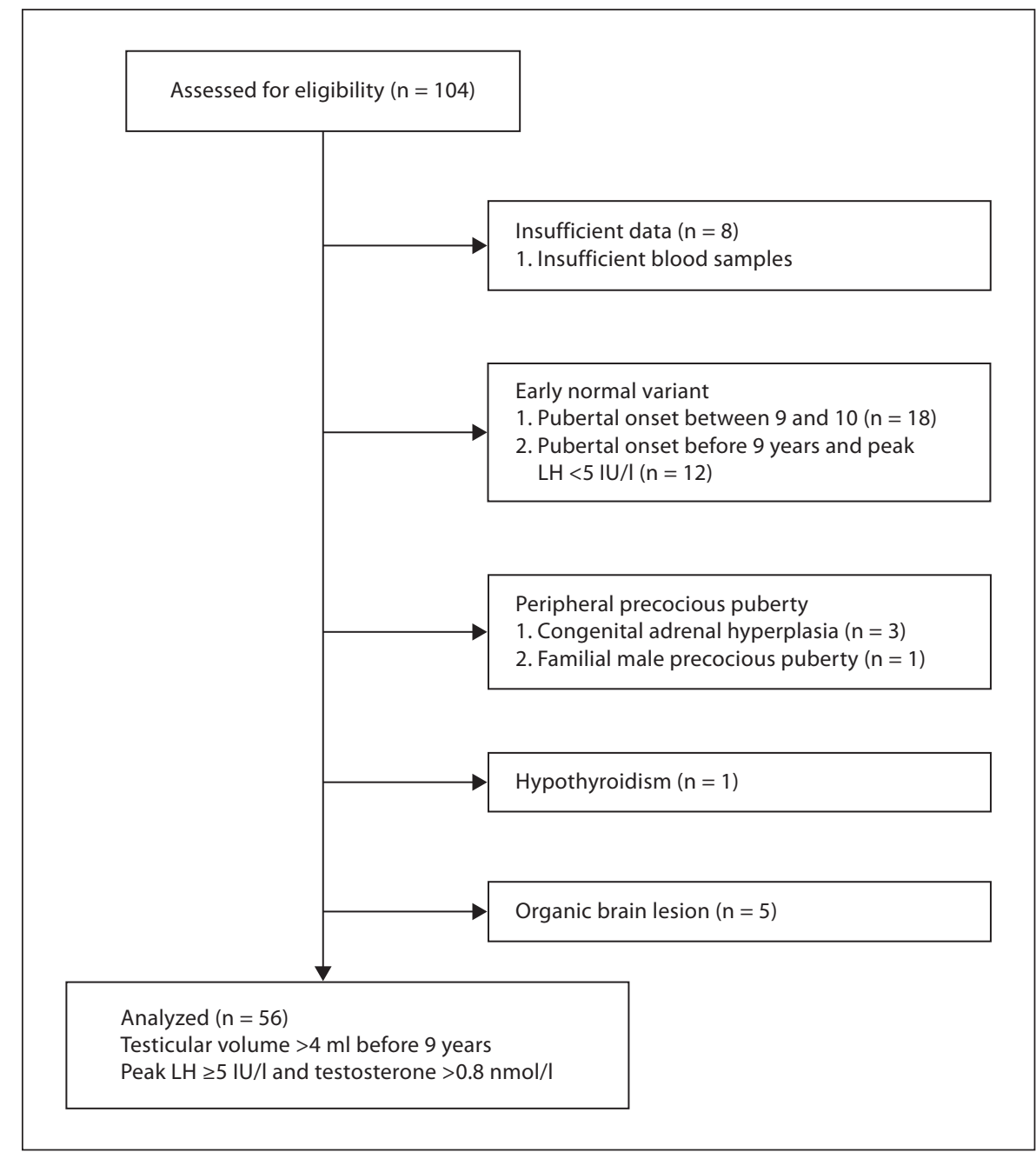

\section{Results}

\section{Population Characteristics}

Clinical characteristics are shown in table 1. Of the 56 children whose data were included in the final analysis, mean age at diagnosis was $8.7 \pm 1.0$ years. The majority of children were of normal weight ( $\mathrm{n}=28,50 \%)$, while 15 (26\%) children were overweight, and 13 (23\%) obese. The average BMI SDS was $1.1 \pm 1.0$. Obese boys were significantly younger at pubertal onset than normal-weight boys. Although mean bone age did not differ in normal-weight and obese boys, differences between bone age and chronological age (BA-CA) were significantly greater in obese boys. Baseline testicular volume and pubic hair stage were similar in the three study groups.

Influence of BMI on LH Response

\section{BMI and Hormonal Parameters}

Basal LH levels, as well as $\mathrm{LH}$ response to $\mathrm{GnRH}$ stimulation tests, were segregated by BMI status (table 2). The basal LH and peak-stimulated LH levels were lower in overweight subjects and lower still in obese subjects. Peak LH levels after GnRH stimulation were 19.8 $\pm 8.8,9.0 \pm 3.5$, and $8.1 \pm 4.0 \mathrm{mIU} / \mathrm{ml}$ among normal weight, overweight, and obese subjects, respectively ( $p<0.001$ for all comparisons). The peak-stimulated LH occurred at $30 \mathrm{~min}$ and progressively declined over the remainder of the test (fig. 2). The basal testosterone and peak-stimulated testosterone levels were also significantly lower in obese boys relative to those in normalweight boys.

Correlation analyses were performed in all subjects; figure 3 details statistically significant correlations. We found a negative association between BMI and peak- 
Fig. 2. GnRH stimulation tests in normal, overweight, and obese subjects. $\mathrm{p}<0.001$ in all time points in the three study groups. Results are presented as mean $\pm \mathrm{SE}$.

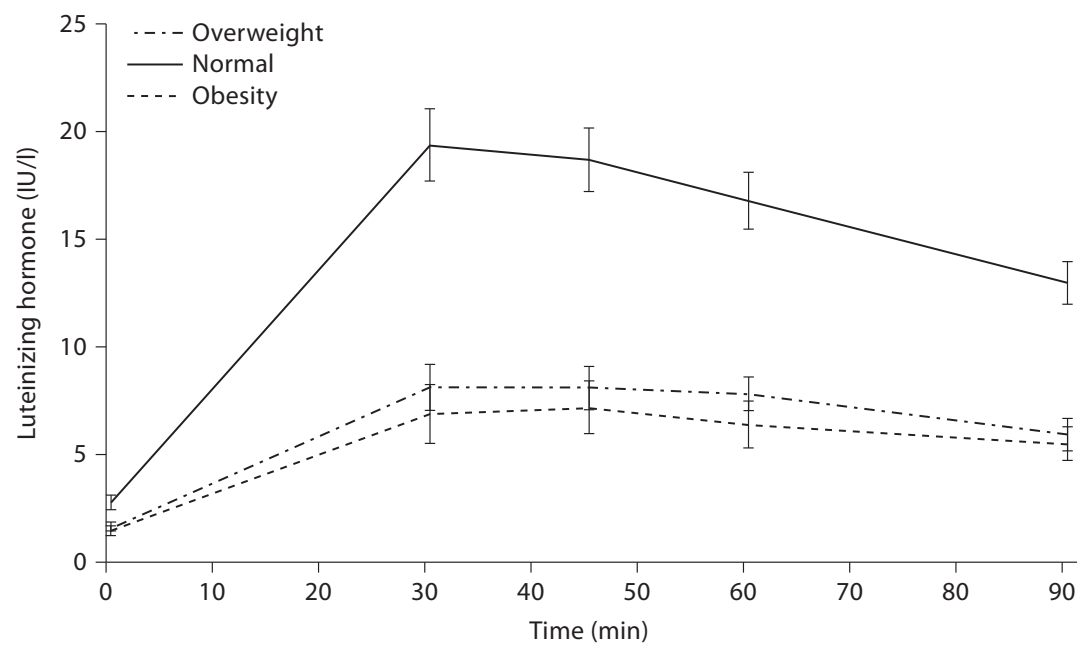

Table 1. Baseline characteristics of study subjects stratified by BMI

\begin{tabular}{|c|c|c|c|c|c|}
\hline Variable & $\begin{array}{l}\text { Total } \\
(\mathrm{n}=56)\end{array}$ & $\begin{array}{l}\text { Normal } \\
(\mathrm{n}=28)\end{array}$ & $\begin{array}{l}\text { Overweight } \\
(\mathrm{n}=15)\end{array}$ & $\begin{array}{l}\text { Obese } \\
(n=13)\end{array}$ & $\mathrm{p}$ value \\
\hline Age at detection, years & $8.7 \pm 1.0$ & $8.8 \pm 1.1$ & $8.7 \pm 0.9$ & $8.6 \pm 1.1$ & 0.022 \\
\hline Height SDS & $1.3 \pm 1.1$ & $1.2 \pm 0.9$ & $0.9 \pm 0.9$ & $1.9 \pm 1.1$ & 0.005 \\
\hline Weight SDS & $1.4 \pm 0.9$ & $0.7 \pm 0.5$ & $1.4 \pm 0.5$ & $2.4 \pm 0.4$ & $<0.001$ \\
\hline BMI & $21.9 \pm 4.4$ & $18.5 \pm 1.3$ & $22.6 \pm 1.0$ & $26.4 \pm 3.0$ & $<0.001$ \\
\hline BMI SDS & $1.1 \pm 1.0$ & $0.3 \pm 0.5$ & $1.4 \pm 0.2$ & $2.2 \pm 0.5$ & $<0.001$ \\
\hline Testicular volume, ml & $6.3 \pm 2.3$ & $6.8 \pm 2.2$ & $5.9 \pm 1.7$ & $6.1 \pm 1.3$ & 0.658 \\
\hline Bone age, years & $12.2 \pm 1.1$ & $12.4 \pm 1.2$ & $12.3 \pm 1.1$ & $12.2 \pm 1.1$ & 0.884 \\
\hline Bone age SDS & $3.9 \pm 1.3$ & $3.8 \pm 1.4$ & $3.4 \pm 0.7$ & $4.4 \pm 1.3$ & 0.101 \\
\hline BA-CA, years & $2.8 \pm 1.1$ & $2.7 \pm 1.1$ & $2.4 \pm 0.6$ & $3.2 \pm 1.1$ & 0.039 \\
\hline
\end{tabular}

Table 2. Hormonal values of study subjects stratified by BMI

\begin{tabular}{|c|c|c|c|c|}
\hline Variable & $\begin{array}{l}\text { Normal } \\
(\mathrm{n}=28)\end{array}$ & $\begin{array}{l}\text { Overweight } \\
(\mathrm{n}=15)\end{array}$ & $\begin{array}{l}\text { Obese } \\
(n=13)\end{array}$ & $\mathrm{p}$ value \\
\hline LH at baseline, IU/l & $2.7 \pm 1.7$ & $1.6 \pm 0.8$ & $1.4 \pm 0.8$ & 0.006 \\
\hline Peak LH, IU/l & $19.8 \pm 8.8$ & $9.0 \pm 3.5$ & $8.1 \pm 4.0$ & $<0.001$ \\
\hline FSH at baseline, IU/l & $3.4 \pm 2.3$ & $2.3 \pm 1.1$ & $2.0 \pm 1.0$ & 0.017 \\
\hline Peak FSH, IU/l & $9.0 \pm 6.8$ & $6.6 \pm 2.3$ & $6.8 \pm 1.7$ & 0.157 \\
\hline Testosterone at baseline, $\mathrm{nmol} / \mathrm{l}$ & $1.7 \pm 0.2$ & $1.0 \pm 0.8$ & $0.9 \pm 0.3$ & $<0.001$ \\
\hline Peak LH/FSH ratio & $3.1 \pm 2.0$ & $1.5 \pm 0.9$ & $1.2 \pm 0.6$ & $<0.001$ \\
\hline
\end{tabular}




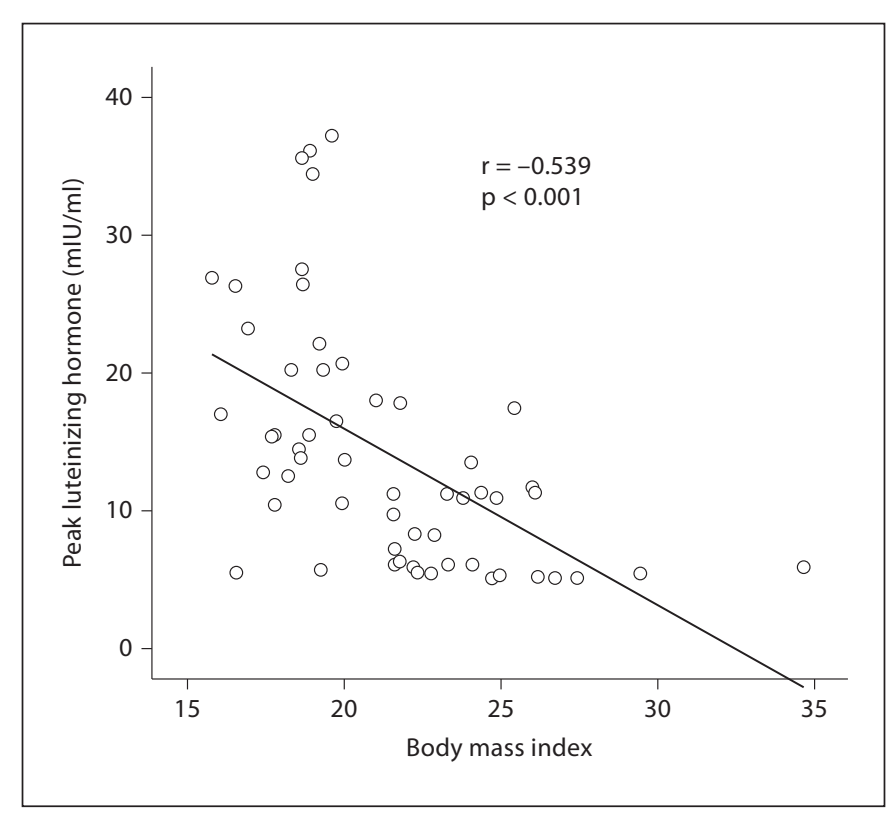

Fig. 3. Correlation between peak $\mathrm{LH}$ to $\mathrm{GnRH}$ stimulation tests and BMI in boys with precocious puberty.

Table 3. Univariate analysis of peak-stimulated LH levels associated with various parameters in all subjects $(n=56)$

\begin{tabular}{lrr}
\hline Parameter & $\mathrm{R}$ & $\mathrm{p}$ value \\
\hline Age at detection & 0.308 & 0.194 \\
Height SDS & -0.040 & 0.752 \\
Weight SDS & -0.499 & 0.001 \\
BMI SDS & -0.552 & $<0.001$ \\
Bone age & 0.268 & 0.115 \\
Basal LH & 0.490 & $<0.001$ \\
Basal FSH & 0.673 & $<0.001$ \\
Basal testosterone & 0.510 & $<0.001$ \\
\hline
\end{tabular}

Table 4. Multivariate analysis of factors associated with peak $\mathrm{LH}$ values $\left(\mathrm{n}=56, \mathrm{r}^{2}=0.741, \mathrm{p}<0.001\right)$

\begin{tabular}{lcll}
\hline Variable & Estimate & SE & p value \\
\hline BMI SDS & -2.632 & 0.937 & $<0.001$ \\
Basal LH & 2.060 & 0.468 & $<0.001$
\end{tabular}

Stepwise multivariate regression analysis containing the following independent variables entered in to the model: age at detection, BMI SDS, weight SDS, height SDS, bone age, Tanner stage, basal LH, basal FSH and basal testosterone levels.

Influence of BMI on LH Response stimulated LH levels $(r=-0.539, p<0.001)$. Peak-stimulated testosterone levels were significantly, negatively correlated with BMI $(\mathrm{r}=-0.406, \mathrm{p}<0.001)$.

\section{Determinants of Peak LH Response to GnRH Stimulation Tests}

Univariate analysis of factors influencing peak LH is summarized in table 3. Peak-stimulated LH levels were positively correlated with basal LH levels, basal testosterone levels, and basal FSH levels. Furthermore, LH levels exhibit a significant negative association with BMI SDS, and weight SDS (table 3). Age at detection, height SDS, and bone age were not significantly correlated with peakstimulated LH levels.

In a stepwise multivariate regression analysis including age at detection, BMI SDS, weight SDS, height SDS, bone age, testicular volume, basal LH, basal FSH and basal testosterone levels as independent variables, and tested in a model with peak LH as dependent variable, BMI SDS and basal LH levels were identified as significant independent predictors for peak LH (table 4). BMI SDS was inversely correlated with, and basal LH levels positively correlated with, peak LH levels.

\section{Discussion}

Our study shows that increased BMI is a major negative determinant of LH levels evoked by GnRH stimulation in boys with precocious puberty. These data suggest that excess adiposity may suppress the hypothalamicpituitary-gonadal axis in boys. Obese boys also enter puberty at an earlier age than children of normal weight, and exhibit more advanced bone age in the current study.

Only a few published studies have evaluated the association between excess weight and the timing of secondary sexual characteristic appearance in boys. In a population-based study, Wang [22] showed that early maturing boys were less likely to be obese. Biro et al. [8] found that boys with greater fat mass, as measured by the sum of skin folds, had less advanced sexual maturation by age 12 years and that boys who had a higher BMI and greater adiposity reached all maturation stages at more advanced ages. In contrast to these studies, Denzer et al. [7] reported pubertal maturation showed no evidence for a shift in pubarche or testicular growth in obese boys. In another study by Sandhu et al. [23], boys with a higher prepubertal BMI experienced earlier onset of puberty. Also, Sorensen et al. [24] reported that age-adjusted BMI was negatively associated with age at onset of testicular growth as 
well as of genital and pubic hair development. In a small Israeli study, obese boys showed no difference in age at testicular or genital enlargement compared to agematched controls [25]. Although previous research is conflicting, our results were consistent with a negative relationship between BMI and age of pubertal onset in boys. These differences may be explained by the differences in ethnic background and assessment of pubertal stage. The strengths of our study rely on the fact that all pubertal examinations were done by one pediatric endocrinologist and the testicular volume was estimated by palpation instead of visual grading or self-assessment. Our study showed that peak LH and testosterone levels in obese boys were decreased, while growth was simultaneously accelerated compared to boys of normal weight. The mechanisms underlying the putative association between childhood obesity and decreased LH levels remain unclear. In adult males, there is an inverse relationship between plasma total testosterone and BMI $[26,27]$. This inverse relationship between total testosterone and subcutaneous adipose tissue appears to stem from variations in sex hormone-binding globulin (SHBG) levels. Low total testosterone levels were frequently found in obese subjects together with reduced levels of SHBG and free testosterone $[28,29]$. On the other hand, weight loss SHBG levels increased, showing a negative linear correlation with BMI [30]. This may be related to a low serum basal LH level as well as a lower LH pulse amplitude as found in obese men [31]. Also, visceral adiposity is associated with elevated concentrations of insulin, C-peptide, and glucose intolerance, which are negatively correlated with total and calculated free testosterone levels [32]. Furthermore, in obese men, elevated estrogen and reduced testosterone levels may result from increased aromatase activity in the enlarged adipose tissue reservoirs [33]. Increased bioavailability of circulating sex steroid influences both somatic and central nervous system developmental maturation [34]. Adrenal androgens might represent a critical link between adipose tissue stores and timing of puberty. The hypothalamic-pituitary axis is more sensitive to sex steroid-negative feedback during early puberty [35]. So, excess androgen or estrogen exposure in obese boys may suppress LH secretion through negative feedback. The combination of these various hormonal stimuli may have regulatory functions on the hypothalamic-pituitary-gonadal axis. There have been few studies on sex hormones and GnRH in children. In obese early prepubertal girls, a significant attenuation of sleeprelated LH production has been reported, while excess adiposity appears to accelerate pubertal onset concomi- tant with promotion of $\mathrm{GnRH}$ and gonadotropin secretion during sleep [14, 36]. Denzer et al. [7] suggested a link between BMI and low circulating androgens in adolescent boys despite normal testis volumes and accelerated growth relative to normal-weight boys. In another study, LH levels were significantly lower in obese boys compared to non-obese controls [37].

There were limitations to our study. We were unable to assess other hormones associated with regulation of puberty, such as estradiol, SHBG, and free testosterone. Also, it will be desirable if more accurate assessment of initiation of puberty by ultrasonography was available. Evaluation of boys with normal puberty will be needed to further validate and characterize the effect of BMI on LH. Additionally, body fat mass was assessed with BMI, a surrogate measure of adiposity. In boys, the testosterone effects on muscle mass interfering with BMI are a measure of adiposity. Further studies might consider a more rigorous body fat measurement, such as dual-energy X-ray absorptiometry.

In conclusion, our results demonstrated a decrease in $\mathrm{LH}$ and testosterone levels dependent on degree of obesity in boys with precocious puberty. Our data highlighted the need to consider BMI when interpreting the results of GnRH stimulation tests in boys. This is the first study suggesting that a higher BMI during early puberty is associated with a reduction in LH evoked by $\mathrm{GnRH}$ stimulation in boys, despite paradoxical advances in pubertal onset. Further studies are required to gain more insight into the mechanism leading to lower testosterone and $\mathrm{GnRH}$-stimulated LH levels in boys with precocious puberty.

\section{Disclosure Statement}

The authors have no conflicts of interest to disclose.

\begin{tabular}{|c|c|}
\hline References & $\begin{array}{l}\text { Han JC, Lawlor DA, Kimm SY: Childhood } \\
\text { obesity. Lancet 2010;375:1737-1748. } \\
2 \text { Ogden CL, Carroll MD, Curtin LR, McDow- } \\
\text { ell MA, Tabak CJ, Flegal KM: Prevalence of } \\
\text { overweight and obesity in the United States, } \\
\text { 1999-2004. JAMA 2006;295:1549-1555. } \\
3 \text { Burt Solorzano CM, McCartney CR: Obesity } \\
\text { and the pubertal transition in girls and boys. } \\
\text { Reproduction 2010;140:399-410. } \\
4 \text { Kaplowitz PB: Link between body fat and the } \\
\text { timing of puberty. Pediatrics 2008;121(suppl } \\
\text { 3):S208-S217. }\end{array}$ \\
\hline
\end{tabular}

Lee/Park/Ko/Kim/Hwang 
5 Cali AM, Caprio S: Obesity in children and adolescents. J Clin Endocrinol Metab 2008; 93:S31-S36.

-6 Ahmed ML, Ong KK, Dunger DB: Childhood obesity and the timing of puberty. Trends Endocrinol Metab 2009;20:237-242.

7 Denzer C, Weibel A, Muche R, Karges B, Sorgo W, Wabitsch M: Pubertal development in obese children and adolescents. Int J Obes (Lond) 2007;31:1509-1519.

8 Biro FM, Khoury P, Morrison JA: Influence of obesity on timing of puberty. Int J Androl 2006;29:272-277, discussion 286-290.

-9 Carel JC, Leger J: Clinical practice. Precocious puberty. N Engl J Med 2008;358:23662377.

10 Roa J, Garcia-Galiano D, Castellano JM, Gaytan F, Pinilla L, Tena-Sempere M: Metabolic control of puberty onset: new players, new mechanisms. Mol Cell Endocrinol 2010; 324:87-94.

-11 Quennell JH, Mulligan AC, Tups A, Liu X, Phipps SJ, Kemp CJ, Herbison AE, Grattan DR, Anderson GM: Leptin indirectly regulates gonadotropin-releasing hormone neuronal function. Endocrinology 2009; 150 : 2805-2812.

12 Fernandez-Fernandez R, Martini AC, Navarro VM, Castellano JM, Dieguez C, Aguilar E, Pinilla L, Tena-Sempere M: Novel signals for the integration of energy balance and reproduction. Mol Cell Endocrinol 2006; 254-255:127-132.

13 Zeinoaldini S, Swarts JJ, Van de Heijning BJ: A signaling role for leptin in puberty onset in female rats? J Pediatr Endocrinol Metab 2006;19:1239-1247.

14 McCartney CR, Prendergast KA, Blank SK, Helm KD, Chhabra S, Marshall JC: Maturation of luteinizing hormone (gonadotropinreleasing hormone) secretion across puberty: evidence for altered regulation in obese peripubertal girls. J Clin Endocrinol Metab 2009;94:56-66.

15 Bordini B, Littlejohn E, Rosenfield RL: Blunted sleep-related luteinizing hormone rise in healthy premenarcheal pubertal girls with elevated body mass index. J Clin Endocrinol Metab 2009;94:1168-1175.

16 Birkebaek NH, Lange A, Holland-Fischer P, Kristensen K, Rittig S, Vilstrup H, Handberg A, Gronbaek H: Effect of weight reduction on insulin sensitivity, sex hormone-binding globulin, sex hormones and gonadotrophins in obese children. Eur J Endocrinol 2010; 163:895-900.

\section{$>17 \mathrm{~S}$}

Sklar CA, Rothenberg S, Blumberg D, Oberfield SE, Levine LS, David R: Suppression of the pituitary-gonadal axis in children with central precocious puberty: Effects on growth, growth hormone, insulin-like growth factor I, and prolactin secretion. J Clin Endocrinol Metab 1991;73:734-738.

18 Prader A: Testicular size: assessment and clinical importance. Triangle 1966;7:240243.

19 Marshall WA, Tanner JM: Variations in the pattern of pubertal changes in boys. Arch Dis Child 1970;45:13-23.

20 Greulich WW, Pyle SI: Radiologic Atlas of Skeletal Development of the Hand and Wrist, ed 2. Standford, Stanford University Press, 1959.

21 Moon JS, Lee SY, Nam CM, Choi JM, Choe BK, Seo JW, Oh K, Jang MJ, Hwang SS, Yoo MH, Kim YT, Lee CG: 2007 Korean National Growth Charts: review of developmental process and an outlook. Korean J Pediatr 2008;51:1-25.

22 Wang Y: Is obesity associated with early sexual maturation? A comparison of the association in american boys versus girls. Pediatrics 2002;110:903-910.

23 Sandhu J, Ben-Shlomo Y, Cole TJ, Holly J, Davey Smith G: The impact of childhood body mass index on timing of puberty, adult stature and obesity: a follow-up study based on adolescent anthropometry recorded at Christ's Hospital (1936-1964). Int J Obes (Lond) 2006;30:14-22.

24 Sorensen K, Aksglaede L, Petersen JH, Juul A: Recent changes in pubertal timing in healthy Danish boys: associations with body mass index. J Clin Endocrinol Metab 2010; 95:263-270.

25 Laron Z: Is obesity associated with early sexual maturation? Pediatrics 2004;113:171172.

26 Svartberg J, von Muhlen D, Sundsfjord J, Jorde R: Waist circumference and testosterone levels in community dwelling men. The Tromso Study. Eur J Epidemiol 2004;19:657663.
27 Haffner SM: Sex hormones, obesity, fat distribution, type 2 diabetes and insulin resistance: epidemiological and clinical correlation. Int J Obes Relat Metab Disord 2000; 24(suppl 2):S56-S58.

28 Abate N, Haffner SM, Garg A, Peshock RM, Grundy SM: Sex steroid hormones, upper body obesity, and insulin resistance. J Clin Endocrinol Metab 2002;87:4522-4527.

29 Hautanen A: Synthesis and regulation of sex hormone-binding globulin in obesity. Int $\mathrm{J}$ Obes Relat Metab Disord 2000;24(suppl 2): S64-S70.

30 Strain G, Zumoff B, Rosner W, Pi-Sunyer X: The relationship between serum levels of insulin and sex hormone-binding globulin in men: the effect of weight loss. J Clin Endocrinol Metab 1994;79:1173-1176.

- 31 Giagulli VA, Kaufman JM, Vermeulen A: Pathogenesis of the decreased androgen levels in obese men. J Clin Endocrinol Metab 1994;79:997-1000.

-32 Seidell JC, Bjorntorp P, Sjostrom L, Kvist H, Sannerstedt R: Visceral fat accumulation in men is positively associated with insulin, glucose, and C-peptide levels, but negatively with testosterone levels. Metabolism 1990; 39:897-901.

33 Vermeulen A, Kaufman JM, Goemaere S, van Pottelberg I: Estradiol in elderly men. Aging Male 2002;5:98-102.

34 Rosenfield RL, Bordini B: Evidence that obesity and androgens have independent and opposing effects on gonadotropin production from puberty to maturity. Brain Res 2010;1364:186-197.

35 Kelch RP, Kaplan SL, Ghumbach MM: Suppression of urinary and plasma follicle-stimulating hormone by exogenous estrogens in prepubertal and pubertal children. J Clin Invest 1973;52:1122-1128.

-36 Bordini B, Littlejohn E, Rosenfield RL: LH dynamics in overweight girls with premature adrenarche and slowly progressive sexual precocity. Int J Pediatr Endocrinol 2010; 2010:pii 724696

-37 Taneli F, Ersoy B, Ozhan B, Calkan M, Yilmaz O, Dinc G, Genc A, Taneli C: The effect of obesity on testicular function by insulin-like factor 3 , inhibin $B$, and leptin concentrations in obese adolescents according to pubertal stages. Clin Biochem 2010;43: $1236-1240$ 